\title{
AIRCRAFT PRODUCTION - ECOLOGICAL ASSESSMENT IN THE PRE-DESIGN STAGE
}

\author{
M. Weiss ${ }^{1}$ and V. Gollnick ${ }^{2}$ \\ German Aerospace Center, Hamburg, Germany, 21079
}

\begin{abstract}
The increasing relevance of sustainable awareness needs the development of methods for a better understanding of the environmental impacts of production processes. Here a method is introduced for modeling and assessing these impacts of manfacturing an aircraft in the early design phase. It uses mathematical models to calculate the caused material- and energy flows of the several different production processes. The method has been applied to a short haul aircraft. Two competing models have been assembled to assess the differences in the environmental impact between aluminum-based and composite-based structures. In addition to the different materials used, both models contain the specific manufacturingtechnologies associated with those materials. The results have been analyzed and reviewed.
\end{abstract}

\section{Nomenclature}

CFRP $=$ Carbon Fibre Reinforced Plastic

$E_{\text {el }} \quad=$ Total process power

$P_{\text {in }} \quad=$ Engine power

$V \quad=$ Cutting volume

$Q=$ Material removal rate

$M_{\text {spec }} \quad=$ Specific emission

GWP $\quad=$ Global Warming Potential

$A P=$ Acidification Potential

$A D P=$ Abiotic Depletion Potential

GABI = Life Cycle Assessment Tool / Database (Ganzheitliche Bilanzierung)

GEMIS = Life Cycle Assessment Tool / Database (Global Emissions Model for Integrated Systems)

\section{Introduction}

$\mathrm{T}$ he Hamburg DLR Institute for Air Transportation Systems develops solutions for conducting Life Cycle Assessment regarding not only the aircraft, but also the remaining elements and operational processes of the Air Transportation System. Thereby the life stages development, production, operation and disposal are balanced. The paper addresses the manufacturing stage of a civil aircraft, to be evaluated in the early design stage. The presented model gives an inspiration how to approach the comprehensive work of balancing the environmental impact of producing an aircraft. By now, the model is limited by taking the aircraft primary structure into account only, but the procedure can be extended to other system elements of an aircraft as well, provided, that sufficient data of the manufacturing processes is available.

The aim of this paper is to recommend how to calculate and evaluate the environmental impact caused by the production of commercial aircraft. The manufacturing phase involves the extraction and production of raw materials, their processing into finished components as well as their assembly.

\footnotetext{
${ }^{1}$ Scientist, Institute of Air Transportation Systems, Blohmstrasse 18, 21079 Hamburg, GERMANY

${ }^{2}$ Head of Institute, Institute of Air Transportation Systems, Blohmstrasse 18, 21079 Hamburg, GERMANY
} 
A method is presented for modelling the ecological inventory and analyses of its impact potential. It is applied exemplarily on the process chains of producing aluminium and carbon fibre structured components of an aircraft. First, the fundamentals of an ecological single process assessment is shown, based on the life cycle assessment method ISO14040 [Ref. 2]. The whole procedure has been realized in a tool chain which has been used for modelling and analysing the two different process chains mentioned above. The main results are presented in this paper.

\section{Method and model}

In accordance to the international guideline ISO14040 [Ref. 2] the manufacturing process was divided into a series of single processes which are linked to the environment by a set of material or energy flows. After modelling the manufacturing chain, including numerous single process steps the input and output of each process were balanced and transferred to the impact potential to the environment. As shown in Fig. 1, the balanced inventories of all outputs "e" of a process " $p$ ”, of all processes for manufacturing a part " $k$ " and of all parts for assembling the aircraft are summarized to aggregated flows (material, emissions, etc.). It has to be noted, that the adequate set up of the process steps modeling requires a balance between a minimum level of detail and a sufficient process coverage.

The procedure has been implemented in a software application which uses mathematical models of manufacturing processes to calculate the required material- and energy-inputs as well as waste-outputs. Each model features a series of parameters which enable a detailed adaptation of the process-model to the real process. For the customization of the calculated inputs and outputs, the application provides a comprehensive database with ecological inventories of sample-inputs and -outputs. Those inventories include quantities of emissions and resource-consumption linked to a reference flow of the sample. Based on this data, the inventories of the calculated inputs- and outputs are derived. The sum of those inventories makes up the share of a process-step. To calculate the inventory of the manufacturing of a whole part, the contributions of all relevant process-steps are accumulated for the entire aircraft manufacturing process. The inventories can then be translated into environmental impacts in the form of common impact-categories like $\mathrm{CO}_{2}$-equivalents. However, especially if different production techniques and/or materials are investigated concerning its environmental impact detailed process descriptions are needed, to highlight potential differences.

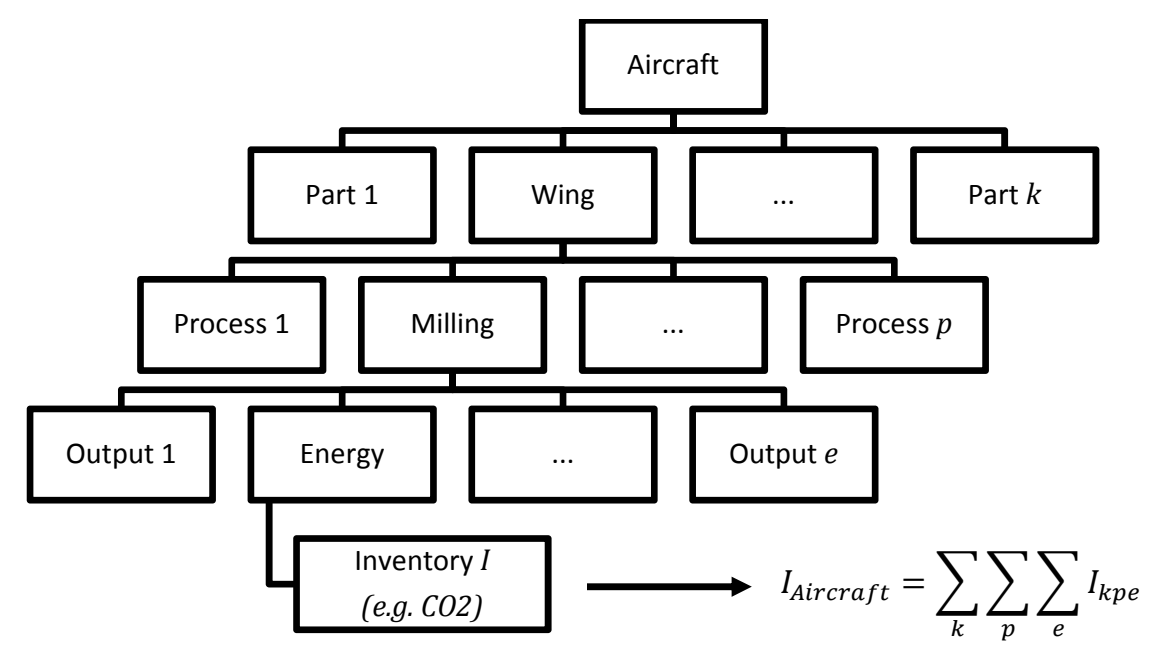

Figure 1. Aggregation of inventories

In the production phase the material passes along different routes described as process chains which consist of a sequence of production steps, so-called single processes. Each single process contains a description of the associated process outputs. For instance, these outputs can be the use of raw materials or waste or energy consumption. In Fig. 2 the simplified path of processing the inventory is illustrated: In the example, the process is described by a the parameter of removal volume V. In the following step, the removal volume is translated to the required machine 2

American Institute of Aeronautics and Astronautics 
power P using a machine specific translation formula. On basis of the calculated power $\mathrm{P}$ the energy demand $\mathrm{E}$ can be derived and combined with a specific flow (e.g. emissions per energy) retrieved from a database. As final result the amount of emissions produced by running the process is outputted.

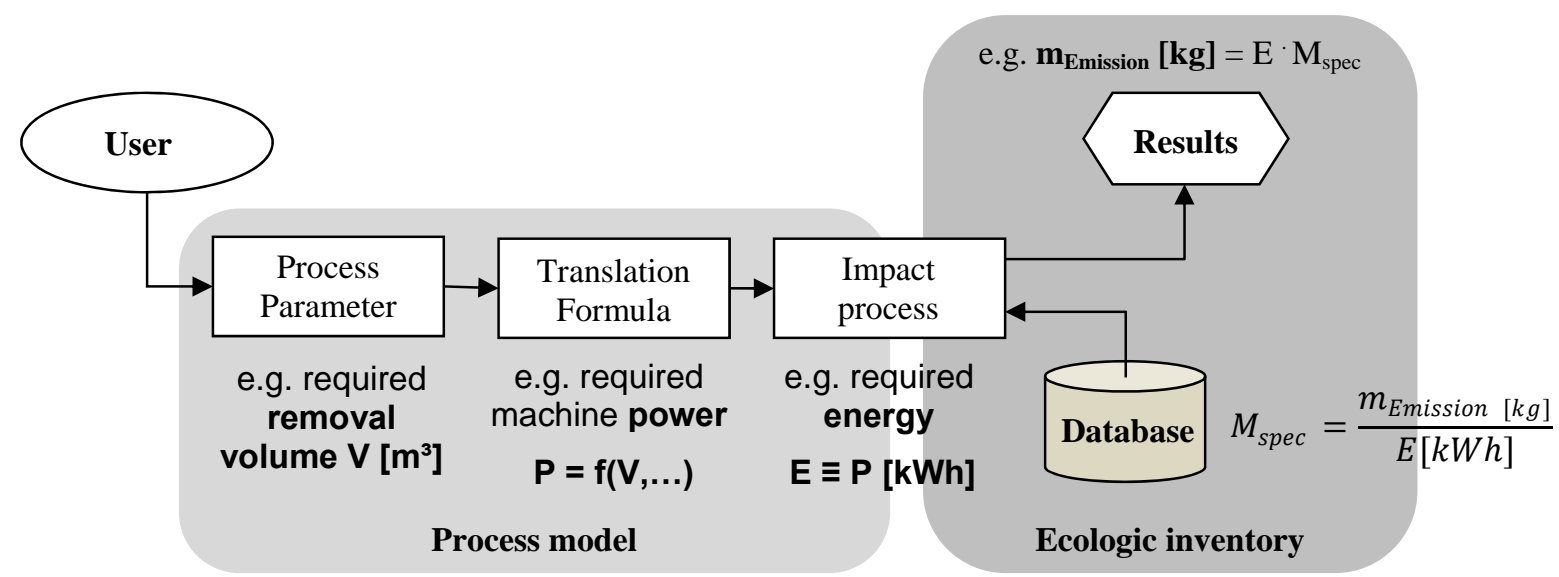

Figure 2. Simplified procedure of calculation

To handle the variety of aircraft components, the main structural parts were subdivided into single sections. Thus the fuselage sections were modelled as fuselage barrels and the wing or empennage sections as wing boxes. The sections consist of single components depending on section type. All parts were approximated by the actual part geometry through standard geometrical bodies to provide a sufficient realism with respect to the production processes. The approximation was mainly done by adjusting iteratively the part thickness as long as the part mass matches the pre-calculated weight as illustrated in Fig. 3 for a rib. Therefore the geometry and the mass of a relevant component are the mandatory references to derive the required energy effort for a certain production step and further on also for the calculation of the associated emissions.

On basis of the pre-calculated part geometry the physical (e.g. "milling”) or chemical (e.g. "etching”) efforts can be derived: For example, modelling a milling procedure, the transfer function combines the output 'energy consumption' with the 3 inputs 'engine power', 'cutting volume' and 'material removal rate' (Eq. 1). The formula is an example how a theoretical process description for calculating the energy $\mathrm{E}_{\mathrm{el}}$ looks like.

with

$$
E_{e l}=P_{i n} \frac{V}{Q} \quad[k W h]
$$

$\begin{array}{lll}\mathrm{E}_{\mathrm{el}} & \text { Total process power } & {[\mathrm{kWh}]} \\ \mathrm{P}_{\mathrm{in}} & \text { Engine power } & {[\mathrm{kW}]} \\ \mathrm{V} & \text { Cutting volume } & {\left[\mathrm{m}^{3}\right]} \\ \mathrm{Q} & \text { Material removal rate } & {\left[\mathrm{m}^{3} / \mathrm{h}\right]}\end{array}$

Looking a little bit more at Eq. 1 the cutting volume is closely linked to the geometry of a certain component. In addition if different materials are investigated, like carbon fibre composites (CFRP) this formular will change, because CFRP components typically do not contain removable volumes. Further it must be noted, that expecially if CFRP is used, future $3^{\text {rd }}$ generation aircraft components, being not designed as "black metal", will show different geometries compared to metallic structures, when the material characteristics are efficiently used to optimize force flow and to minimize mass. 


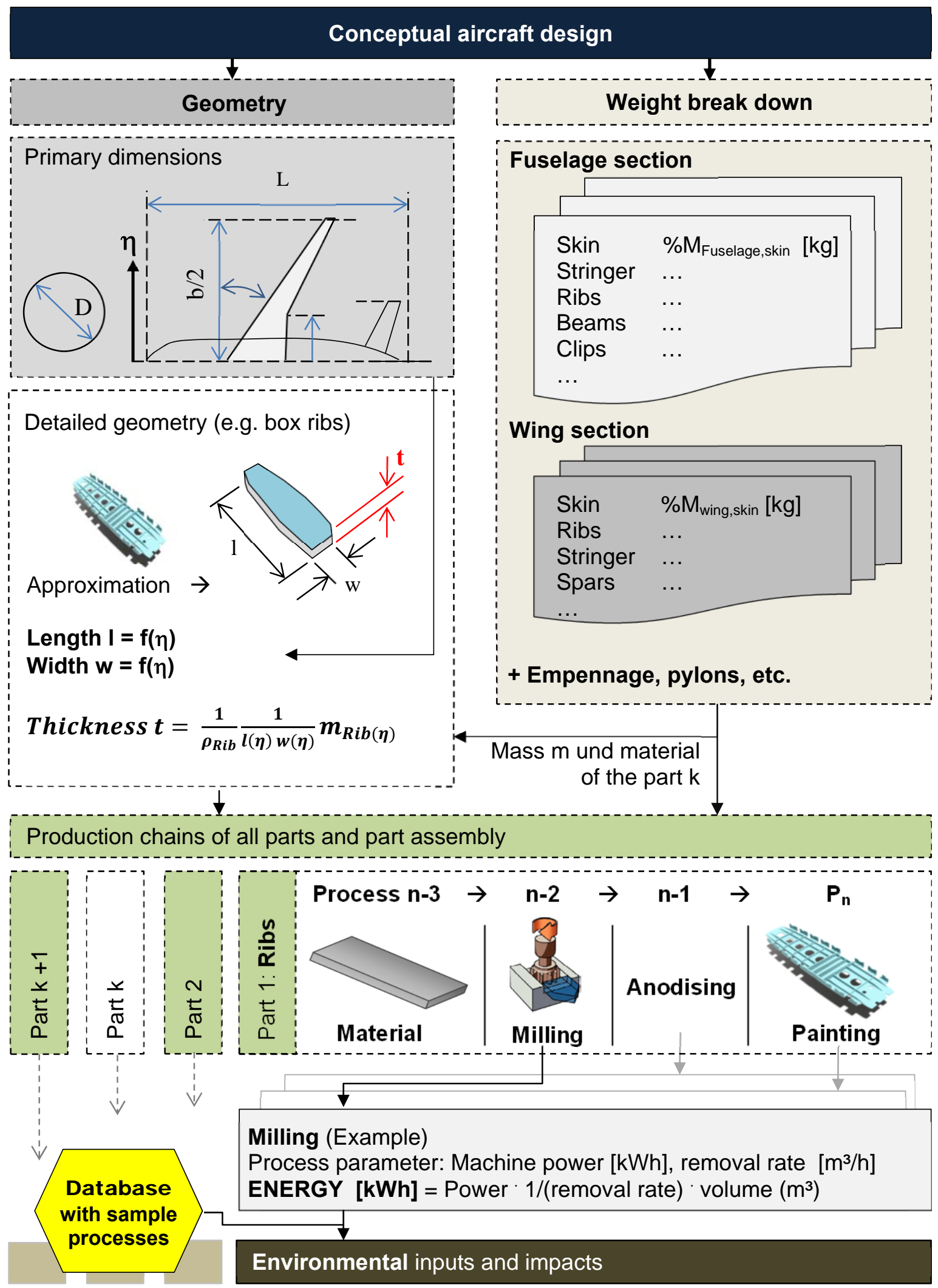

Figure 3: Iterative adjustment of the part geometry and mass estimation using standard geometry bodies 
After calculating the process's output (e.g. electricity consumption), it has to be translated into physical flows (material, emissions, energy ...) in order to balance the environmental impact. For that, databases such as $\mathrm{GaBi}{ }^{\circledR}$ or GEMIS are used which provide relevant emission masses related to the energy mix and effort per production step, based on primary industry data (sample process). Thus, the process outputs can be transferred into environmental relevant flows, applying a similar industrial process available in the database. For instance, the effort of a specific

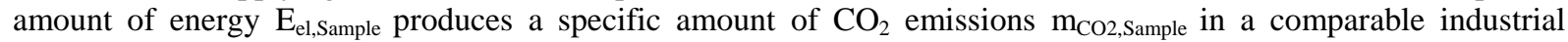
environment. Thus, the overall $\mathrm{CO}_{2}$ emissions can be calculated with Eq. 2. In general, all energy effort or other process's outputs can be allocated to a collection of different material and energy flows applying the procedure above. The mathematical model has to be set-up individually for each process and all together make up the so called inventory.

with

$$
m_{\mathrm{CO} 2}=E_{e l} \frac{m_{\text {CO2,Sample }}}{E_{\text {el,Sample }}}=E_{\text {el }} M_{\text {spec }}
$$

$\begin{array}{lll}\mathrm{E}_{\mathrm{el}} & \text { Total process power } & {[\mathrm{kWh}]} \\ \mathrm{M}_{\text {spec }} & \text { Specific Emissions } & {[\mathrm{kg} / \mathrm{kWh}]}\end{array}$

\section{Impact Analysis}

Estimating the environmental impact is one of the paramount goals of the life cycle assessment. Thereby the different inventory results are translated into a common "impact value" in a specific impact category (e.g. Global Warming, Ozone Depletion, Abiotic Depletion Potential ...). With equivalence factors the different contributions of the materials or emissions are aggregated to an environmental effect, defined according to a reference substance. Thus, on the basis of the inventory analysis the individual contributions are multiplied with the corresponding equivalence factors and summed up. In accordance to the simplified example in Chapter 2 (milling process), the impact estimation is conducted as follow:

As an example, let us assume that the milling process consumes $1 \mathrm{kWh}$. A specific electricity production (e.g. coal-fired plant), retrieved from a database (e.g. GABI®), will result in corresponding flows of carbon dioxide $\mathrm{CO}_{2}$, nitrogen dioxide $\mathrm{NO}_{2}$ and methane $\mathrm{CH}_{4}$ of $1.0 \mathrm{~kg}, 0.4 \mathrm{~g}$ and $0.3 \mathrm{~g}$ per $\mathrm{kWh}$. For investigating the expected impact of the sample-process, the impact potential concerning the "Global Warming Potential” (GWP) will be calculated in the dimension of $\mathrm{kg}-\mathrm{CO}_{2}$-equivalent.

Fig. 3 shows the required calculation steps. Therein, the emissions specific equivalent factors are taken from the Intergovernmental Panel of Climate Change IPCC [Ref. 3]. Taking a certain energy mix into account for the generation of electrical secondary energy a small impact of nitrogen dioxide as well as methane can be seen. The overall result of $1,0128 \mathrm{~kg}-\mathrm{CO}_{2}$-equivalents is mainly driven by the species $\mathrm{CO}_{2}$. Such a result is typical, if electrical energy generation is mainly based on fossile primary energy. If for example a country uses mainly nuclear or wind power the situation will change, which has to be considered for a deeper analysis and and potential overall process improvments. In the same way other impact categories such as "Acidfication Potential" or "Photochemical Ozone Creation Potential” are analysed. Summarizing all impact potentials of each single process of the overall production chain (see Fig. 2) the overall environmental impact of the aircraft manufacturing process can be calculated.
flow
$\times$ equivalence-factor
= damage potential

\begin{tabular}{|c|c|c|c|c|c|}
\hline & $1 \mathrm{~kg} \mathrm{CO} 2$ & $x$ & 1 kg CO2-equiv./ kg CO 2 & $=$ & $1 \mathrm{~kg} \mathrm{CO}_{2}$-equiv. \\
\hline \multirow[t]{3}{*}{ GWP } & $0,00004 \mathrm{~kg} \mathrm{NO} \mathrm{NO}_{2}$ & $x$ & 298 kg CO2-equiv./ kg NO & $=$ & 0,012 kg CO -equiv. \\
\hline & 0,00003 kg $\mathrm{CH}_{4}$ & $\mathrm{x}$ & 25 kg CO2-equiv./ kg $\mathrm{CH}_{4}$ & $=$ & 0,00075 kg CO2-equiv. \\
\hline & & & $\mathbf{G W P}_{100}$ & & $1,0128 \mathrm{~kg} \mathrm{CO}$-equiv. \\
\hline
\end{tabular}

Figure 4. Global Warming Potential of sample milling process per $\mathbf{k W h}$ 


\section{Use Case}

In order to investigate the ecological impacts of different aircraft designs and associated production chains, two models of the production process have been created, representing a typical aluminum based aircraft design and a CFRP based aircraft design. For the latter the a "black metal" approach has been chosen, where aluminum parts have been replaced by CFRP without redesigning the geometry according to the material properties. The aircraft itself is similar to an Airbus A322 type. The models therefore are different in the materials used for the components as well as in the associated manufacturing procedures used for the production. The production chains are modelled for the primary structure components only, such as fuselage, wing and empennage.

On the right Table 1 shows the primary masses of the modelled components by applying preliminary design methods, such as in reference publications , [Ref. 7]. At a first glance there is a significant different in the structural mass up to $45 \%$ in case of the fuselage. However it must be noted, that the presented use case is a rough simplification taking not into account material oriented geometry design. Further experiences in aircraft operations on airfields show, that there a often incidents and accidents observed due to collisions of the aircraft fuselage with gangway and vehicles. Therefore for future more realistic assessments the most appropriate application of CFRP on aircraft from operational point of view needs to be considered despite the challenges of demage detection.

Table 1: Parts by sections (left); component-masses in kilograms (rounded)

\begin{tabular}{|l|l|l|c|c|}
\hline Fuselage parts & Wing box parts & Components & Alu [kg] & CFRP [kg] \\
\hline Skin & skin & Fuselage & 7.800 & 4.300 \\
Stringer & stringer & Wing & 8.400 & 4.700 \\
Rib & rib & HTP & 700 & 400 \\
Clip & Spar & VTP & 400 & 300 \\
floor beams & & Total & 17300 & 9700 \\
\hline
\end{tabular}

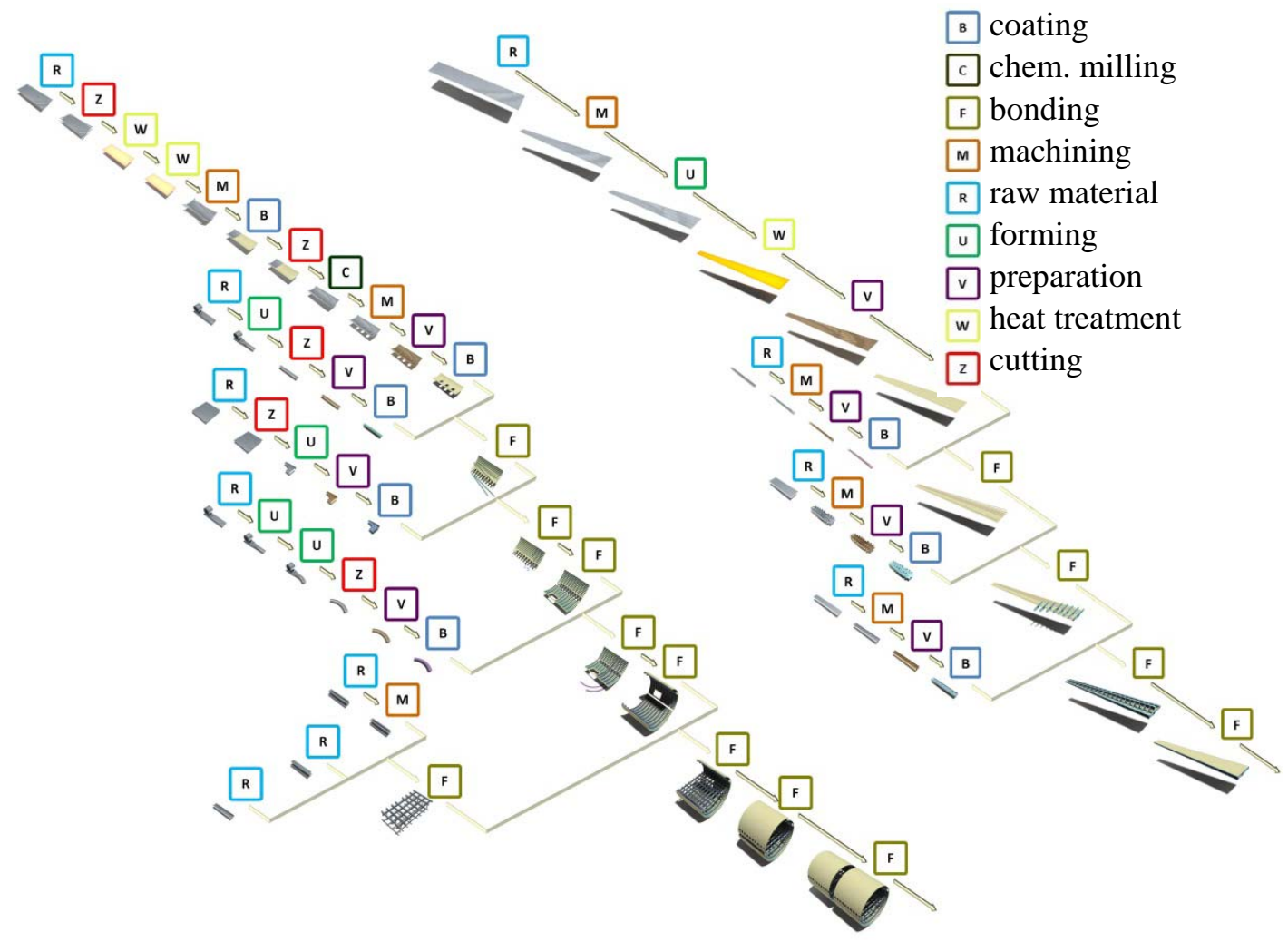

Figure 5: Manufacturing processes of fuselage-barrel (left) and wing-box

6

American Institute of Aeronautics and Astronautics 
The section's process chains were modelled for the aluminium and for the CFRP configuration. The individual processes are significantly different, since other manufacturing methods are used for the CFRP and the aluminium processing. The complete process chain of the airplane's structure production consists of over 500 single processes. An overview about the overall process chains of the sections fuselage barrel and wing box is given in Fig. 5, using aluminium materials. On the right side the individual process at each step of the chain is indicated. Referring to [Ref. 1], the processes are not described in detail in this paper.

For verifying the calculations the results were compared to a study on the environmental impacts of manufacturing a CFRP fuselage from the KIT [Ref. 5]. Also for this purpose the simplications mentioned above make sense to ensure comparability of the methods. The results show a good conformity with the published values there. The deviations, as shown in Fig. 6, are typical due to the fact that the detailed process descriptions as well as the assumed material demand between the study and the calculations here are not completely identical. As a further impact as mentioned before, the assumed electricity mix might influence the results significantly (e.g. fossile $\leftarrow \rightarrow$ nuclear).
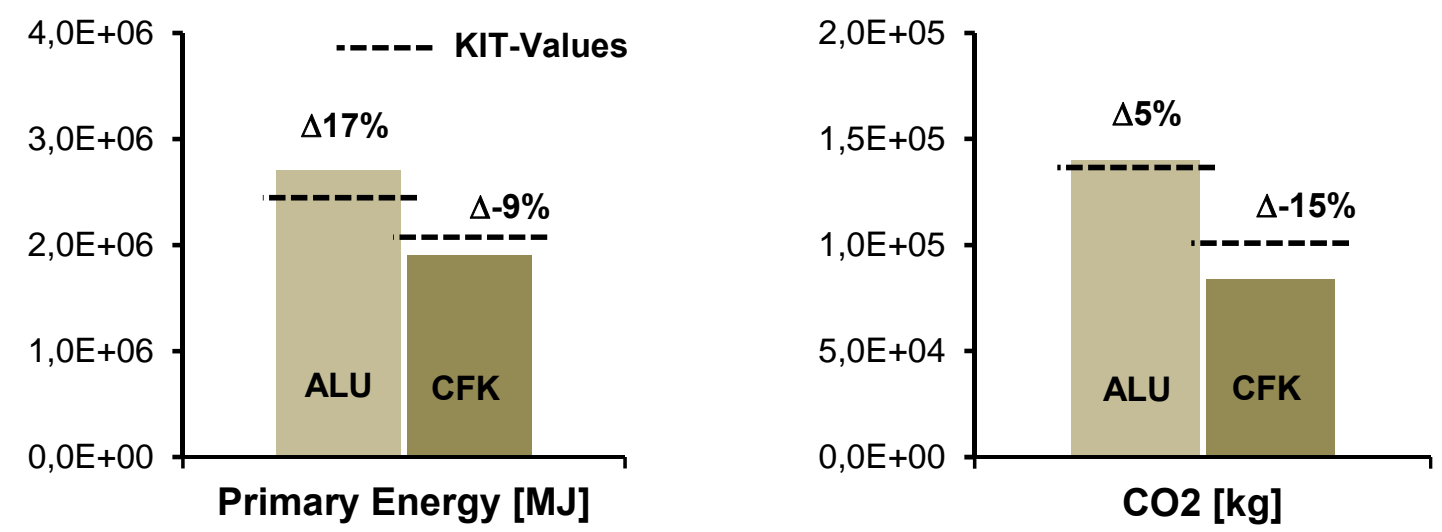

Figure 6: Primary energy (left) and CO2-emissions of aluminum and CFRP manufactured aircraft

The calculated LCI results of the two designs are summarized in Table 2. The primary energy demand for the aluminium construction is $23,7 \%$ higher compared to the CFRP structure. This is due to the fact that a substantial part of the manufacturing process is determined by producing the raw material (aluminium alloy or CF fabric). For the production of fibres (here on PAN-based) a lower primary energy input is required than for the same aluminium based material volume.

Table 2: Summary of emission generation and impact results (Aluminium vs. CFRP)

\begin{tabular}{|c|c|c|c|c|c|}
\hline & & & Aluminium & CFRP & Delta \\
\hline Primary energy & $\mathrm{PE}$ & $\mathrm{MJ}$ & $11,4 \mathrm{E}+6$ & $8,7 \mathrm{E}+6$ & $-23,7 \%$ \\
\hline Carbon dioxide & $\mathrm{CO}_{2}$ & $\mathrm{~kg}$ & $5,85 \mathrm{E}+5$ & $3,96 \mathrm{E}+5$ & $-32,3 \%$ \\
\hline Sulphur dioxide & $\mathrm{SO}_{2}$ & $\mathrm{~kg}$ & $1,81 \mathrm{E}+3$ & $4,98 \mathrm{E}+2$ & $-72,5 \%$ \\
\hline Methane & $\mathrm{CH}_{4}$ & $\mathrm{~kg}$ & $1,02 \mathrm{E}+3$ & $2,06 \mathrm{E}+3$ & $101,9 \%$ \\
\hline Nitrogen oxides & $\mathrm{NO}$ & $\mathrm{kg}$ & $2,26 \mathrm{E}-5$ & $2,12 \mathrm{E}-6$ & $-90,6 \%$ \\
\hline Nitrogen dioxide & $\mathrm{NO}_{2}$ & $\mathrm{~kg}$ & 7,92E-1 & $1,74 \mathrm{E}+2$ & 218-fold \\
\hline Hydrochloride & $\mathrm{HCI}$ & $\mathrm{kg}$ & $4,45 \mathrm{E}+0$ & $8,37 \mathrm{E}+0$ & $88,1 \%$ \\
\hline $\mathbf{G W P}_{\mathbf{1 0 0}}$ & & [kg CO${ }_{2}$-Equiv.] & $6,60 \mathrm{E}+5$ & $4,99 \mathrm{E}+5$ & $-24,4 \%$ \\
\hline AP & & [kg SO${ }_{2}$-Equiv.] & $2,56 \mathrm{E}+3$ & $8,28 E+2$ & $-67,7 \%$ \\
\hline ADP & & [kg Sb-Equiv.] & $3,38 \mathrm{E}+3$ & $3,36 E+3$ & $-0,6 \%$ \\
\hline
\end{tabular}


Additionally, the calculation and evaluation of the emission levels show significant differences between the two manufacturing processes: While $\mathrm{CO}_{2}$ emissions decrease in the transition to CFRP-based structure by $32 \%$, the amounts of methane $\mathrm{CH}_{4}$ doubled and a more than 200-fold increase in nitrogen dioxide emissions $\mathrm{NO}_{2}$ has been calculated. This enormous and process-related increase is mainly due to the pyrolysis of polyacrylonitrile (PAN) to carbon fibres, but also caused by the use of large amounts of nitrogen as a protective gas in the autoclave. But the absolute amounts are not sufficient for a final assessment of the potential impact, so they must be transferred to an appropriate impact category with specific equivalence factors and eventually aggregated.

To calculate the potential environmental impact the procedure shown in chapter 2.2 has been applied. For the Global Warming Potential (GWP) the equivalence values are taken from the IPCC report [Ref. 3] and for the acidification potential (AP) from the CML database [Ref. 4]. Using these equivalence values the environmental impact of the CFRP construction decrease by $24.4 \% \mathrm{~kg} \mathrm{CO}_{2}$-equivalent (GWP) and by $67.7 \% \mathrm{~kg} \mathrm{SO}_{2}$-equivalent (AP). This indicates that the consideration of $\mathrm{CO}_{2}$ and $\mathrm{SO}_{2}$ emissions only overestimates the potential for reducing greenhouse-relevant as well as acid-relevant species! The strong increase in nitrogen dioxide and methane emissions, caused by the CFRP production process of glueing and heating compensate the single advantage of reduced $\mathrm{CO}_{2}$ emissions by almost $8 \%$ impact potential (GWP). The Abiotic Depletion Potential ADP (resources consumption indicator) of both structural concepts is nearly unchanged. Although the CFRP concept needs less material this is reasoned by the higher demand of crude oil resource for CRFP, taking into account its scarcity (Fig. 7).
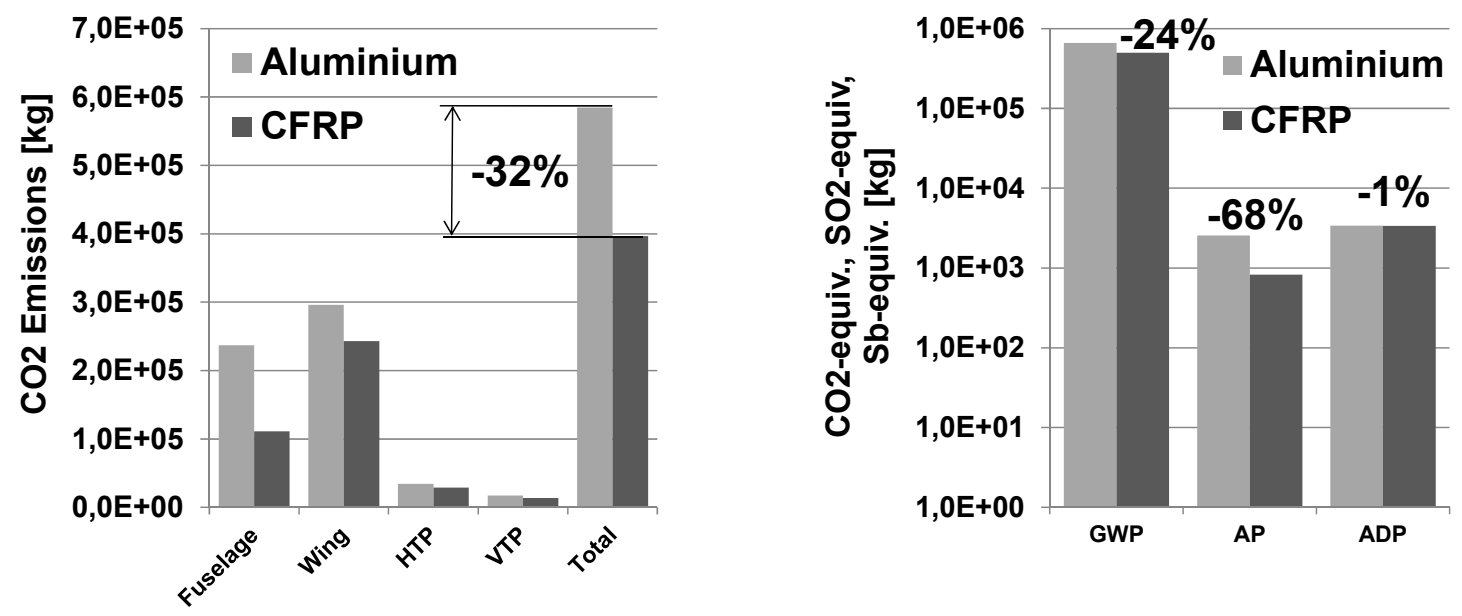

Figure 7: Distribution of CO2-emissions, aluminum / CFRP

Further Fig. 7 also shows, that the fuselage offers the major potential in $\mathrm{CO}_{2}$ reductions, while the tail planes and the wing contribute less. Nevertheless the operational challenges concerning damage risk of fuselage should be taken into account. On the other side concerning the application of laminar flow technologies, especially wing and tail wing designs strongly request for CFRP use due to the expectation of highly smooth surfaces, which are required.

Since the production is composed of many individual steps and processes, the emissions of this stage cannot be explained by one source only. Therefore, a differentiated analysis of the individual processes was performed. Besides the distinguished analysis of the part's contribution (Fig. 7 left), the processes were compared to the overall impact potential. Fig. 8 shows an example of the distribution of the potential impact on the Global Warming Potential caused by producing the fuselage-skin: The raw material production and processing it into semi-finished products play a dominant role in the development of environmental pollution. This is explained by the fact that numerous preliminary processes such as resource extraction or transportation are included. On the other hand, heat treatment processes (e.g. annealing) are also responsible for a relatively high proportion of pollution due to its energy demand. Although these processes are directly linked to the manufacturing chain, there are only few options for its optimization by the aircraft manufacturer. 

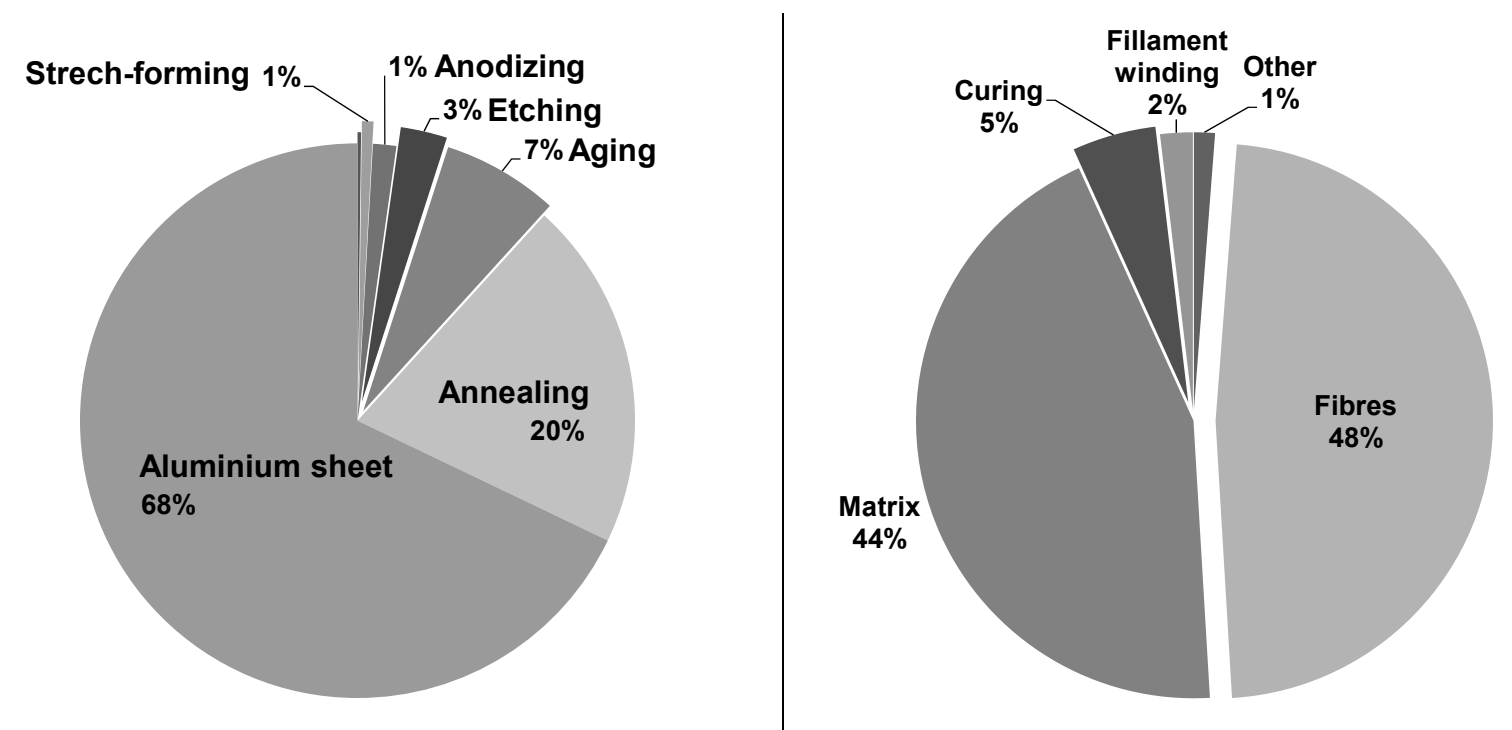

Figure 8: Distribution of GWP during fuselage-skin manufacturing: Alu (left) vs. CFRP

\section{Conclusion}

There is a broad opinion that the production phase in the life-cycle of an aircraft is an undepart concerning environmental impacts. It is true that carbon dioxide emissions are strongly small in the production compared to operational phase (approx.: 1:1500). It is not true, if one considers other species and toxic substances corresponding to the manufacturing process (e.g. waste water or radioactive waste by the electricity production). Furthermore, the emissions are concentrated locally, and thus endangering the regional environment. All of these aspects could not be reflected in this study, but an approach for the pre-required inventory calculations of the aircraft production is introduced.

In this paper, the manufacturing process of a commercial aircraft in its preliminary design stage was assessed from an environmental perspective. The evaluation focuses on the comparison between conventional aluminium structured and a presumed CFRP designed short haul aircraft. The assessment was conducted on the basis of the structure components fuselage, wing and empennage. The specific production chains were modelled and evaluated in accordance to DIN/ISO 14040.

In a detailed analysis the different individual process steps were evaluated with regard to their environmental damage. It has been shown that the production of raw materials caused the highest environmental impact. In addition, especially heat treatment processes have a significant impact on the eco-balance. The evaluation of the production chains has revealed that, on the basis of the assumptions made and from ecological point of view, the CFRP is superior compared to the conventional aluminium construction: On average, the Global Warming Potential can be reduced by $24 \%$ and the Acidification Potential even by $68 \%$. Despite of these advantages, it has to be considered that fibre reinforced composites are based on an abiotic resource (oil).

In the next steps more material oriented geometric design aspects will be considered and also production cost are to be integrated, since in an economic world there is always a trade off between ecological impact and economoical efficiency.

\section{References}

${ }^{1} \mathrm{M}$. Bohlender: Ökologische Bewertung des Herstellungsprozesses von Verkehrsflugzeugen in der Konzeptphase; Institut für Lufttransportsysteme (TU Hamburg / DLR), IB-328-2012-24, Hamburg, 2012

${ }^{2}$ DIN EN ISO 14040, Umweltmanagement - Ökobilanz - Grundsätze und Rahmenbedingungen, Beuth Publishing, Berlin, 2006

${ }^{3}$ P. Forster et al.: Changes in Atmospheric Constituents and in Radiative Forcing. In: Climate Change 2007: The Physical Science Basis. Contribution of Working Group I to the Fourth Assessment Report of the IPCC, Cambridge University Press, Cambridge, NY, USA. 
${ }^{4}$ CML 1996, University Leiden, Netherlands, 2013, www.cml.leiden.edu [accessed May 9, 2013]

${ }^{5}$ K.-R. Bräutigam, M. Achternbosch: Analyse der Umweltauswirkungen bei der Herstellung, Nutzung und Entsorgung von CFK- bzw. Aluminiumrumpfkomponenten im Flugzeugbau, Karlsruher Institute for Technology (KIT), Karlsruhe, 2003

${ }^{6}$ L. van Oers: CML Database; Version 4.1, October 2012, Institute of Environmental Sciences, Leiden University, Niederlande, 2012

${ }^{7}$ D. Howe, Aircraft Conceptual Design Synthesis, John Wiley \& Sons; Edition: New Ed, 2005 